\title{
The effect of co-application of manure on the effectiveness of phosphorus fertilizers for potato culture on old-dusted of dark serozems soil
}

\author{
Z.K. Bobokhonova*, and R.B. Boymurodov \\ Tajik Agrarian University named after Shirinshoh Shohtemur, Dushanbe, Tajikistan
}

\begin{abstract}
In this article is shown, that the results of research are about one of the main problems of agricultural production of the country, the present and future production of early potatoe crop in irrigation place of Hissor district and the way of raising phosphorus fertilizer, that coefficient of use utilizing phosphorus. It is recommended the best recommendation to specialists the scientific analysis.
\end{abstract}

\section{Introduction}

In recent years much attention has been paid to the development of potato growing in the Republic of Tajikistan. The main traditional mountain areas of potato farming usually provide the population with marketable potatoes mainly in the late autumn and winter periods of the year.

For this reason, the problem of early potato growing is particularly relevant, in the valley regions of the republic, in which it will be possible to provide the population with this important and necessary food product throughout the summer season.

The Hissar Valley is one of the main regions of early potato growing in the republic, because it has sufficient bioclimatic and land resources for the wide development of this industry. According to the thermal resources in the Hissar Valley, it is possible to concentrate the cultivation of early potatoes in vertical areas of absolute heights from 600 to $1000 \mathrm{~m}$. above sea level, which is a zone of distribution of dark serozems soil.

According to the data of State Statistics Committee, the area of potato cultivation in the Republic for 1994-2003 on average for the year was 3.2 \%, in the Hissar Valley $2.6 \%$ of the total area with an average yield of 134 and $175 \mathrm{c} /$ ha and gross potato harvest of 283212 and 41247 tons, respectively [1].

Calculations show, that when growing potatoes, even by $30 \%$, the identified potential of the land area is suitable for early potato growing in the Hissar Valley, amounting to more than 23 thousand hectares, with a weighted average yield of $190 \mathrm{t} /$ ha [2], more than 132 thousand tons of marketable potatoes can be produced annually, which can be 3.2 times more than the average annual volume of its production over the last ten-year period.

${ }^{*}$ Corresponding author: intertau-tj@mail.ru 
Consequently, both in the republic as a whole and in the Hissar Valley, the actual potato yield is very low (134 and $175 \mathrm{c} / \mathrm{ha}$ ) and cannot provide the necessary level of development of this industry. Along with many other reasons on the issue of seed breeding, agricultural technology, biotechnology and potato diseases, morphological characteristics, different potato genotypes depending on agroecological factors and their adaptation in different agroecological conditions in different zones of the Republic of Tajikistan Kakhorov (1995); Anvarova (1998); Muminjonov (2003); Partoev, Gulov, Nikhmonov (2019) and many others when conducting research on this issue in Tajikistan, the main reason for the low yield of potatoes in our opinion is still the low availability of mineral fertilizers and the very low efficiency of certain types of fertilizers, in particular phosphorus fertilizers.

Due to the high cost of phosphorus fertilizers, currently the agriculture of the republic is provided with phosphorus by only $20-25 \%$, [3] and it is obvious, that with the traditional technology of applying phosphorus fertilizers, it consists in a continuous surface spreading from autumn with subsequent embedding under plowing as the main fertilizer, it is unlikely to get a sufficiently high effect from the use of expensive phosphorus fertilizers, because it is known that phosphorus fertilizers on dark serozems soil used according to the abovementioned technology have a very low utilization rate in the range of 10-16\% [4].

Therefore, one of the main ways to improve the efficiency of phosphorus fertilizers in these conditions may be to change the existing technology of their application. This was also mentioned by (Pryanishnikov), [5] "that a more complete use of phosphorus can be obtained by local placement of phosphorus fertilizer in the soil, ensuring their minimal interaction with the soil and the maximum approximation of phosphates to the root system of plants" p. 327-365.

However, the maximum possible increase in the efficiency of phosphorus fertilizers can be achieved only by concentrating phosphorus in the zone of distribution of the active root system of the main row crops during the period of their maximum demand for phosphorus at which the active root system of the main row crops can be located at a depth of 25-30 $\mathrm{cm}$, in particular, in potatoes, to a depth of $20-25 \mathrm{~cm}$. In accordance with this, research was carried out to learn the new technology of the main application of phosphorus fertilizers by the tape method for the culture of early potatoes in the conditions of the Hissar Valley. This issue in the old-irrigated on dark serozems soil of Tajikistan is new and insufficiently studied $[9,10]$.

In accordance with the above, the main purpose of the research is to assess the state and prospects of early potato growing in the Hissar Valley and to develop a new technology for applying phosphorus fertilizers for potato crops, that contributes to improving the efficiency of phosphorus fertilizers and the yield of this crop.

In accordance with this, the following tasks were set:

- Analysis of the current state of potato growing in the Hissar Valley;

- To determine the land and bioclimatic resources and prospects for the development of early potato growing in this region;

- To learn the effects of deep basic application of full and half norms of phosphorus in the form of superphosphate on a manure and non-manure background by the tape method before planting potatoes on the yield and quality of potato products;

- To determine the effect of the new technology of applying phosphorus fertilizer on the nature of removal and the value of the phosphorus utilization rate of the plant from superphosphate;

The essence of this method of application is, that the superphosphate and manure, in addition to the traditional continuous application with subsequent sealing under plowing, were introduced along the track of planting potatoes to a depth of $20-25 \mathrm{~cm}$ with a straight tape. To do this, in the loosened soil with a homemade hand-drawn plough (in large areas, horse-drawn ploughs can be used), straight grooves with a depth of 25-30 cm were made 
and at the bottom of these furrows, superphosphate and manure were introduced with a solid tape and then another one was made next to this groove, as a result of which the fertilizer was covered with soil without mixing and after that the seed material was planted.

\section{Materials and methods}

Experience consisting of 10 options. in a three-fold repetition, where four factors were studied: nitrogen, phosphorus, potassium, and manure. The soils - old-irrigated dark serozems soils-are most common in the early potato growing zone of the Hissar Valley. Agrochemical background of the soil for phosphorus is average in the range of 15-30 $\mathrm{mg} / \mathrm{kg}$ P2O5, for mineral nitrogen low-15-17 mg/kg for potassium high-20-30 mg/100 g. Initial norms: N 150, P2O5 and $\mathrm{K} 2 \mathrm{O}$ of $100 \mathrm{~kg} / \mathrm{ha}$, manure of $10 \mathrm{t} / \mathrm{ha}$.

At the same time, the effect of co-application of manure on the effectiveness of phosphorus fertilizers was studied. Chemical analyses of soils, plants and crops were carried out according to generally accepted methods, and mathematical processing according to the method of "Corrected deviations" [7].

\section{Results and discussed}

The results of the research obtained in the experiment (Table.1) indicate a certain positive correlation between the compared options in favor of tape application of phosphorus fertilizers. The increase in yield only due to tape application (option 3 ) is $102 \mathrm{c} / \mathrm{ha}$, which is a very significant increase, which can be economically quite effective.

Table 1. The impact of the new technology of the main application of phosphorus fertilizers and manure on the potato crop and the use of phosphorus utilization rate.

\begin{tabular}{|c|c|c|c|c|c|}
\hline № & Variants & $\begin{array}{c}\text { Average yield } \\
\text { for three years } \\
\qquad \mathrm{c} / \text { ha }\end{array}$ & $\begin{array}{l}\text { Increase } \\
\text { from the } \\
\text { control of } \\
\mathrm{c} / \text { ha }\end{array}$ & $\begin{array}{l}\text { Increase } \\
\text { from } \\
\text { the } \mathrm{c} / \mathrm{ha} \\
\text { factor }\end{array}$ & $\begin{array}{c}\text { Phosphorus } \\
\text { utilization } \\
\text { factor in } \\
\%\end{array}$ \\
\hline 1 & $\begin{array}{l}\text { Control } \\
\text { (without } \\
\text { fertilizers) }\end{array}$ & 97 & & & \\
\hline 2 & $\mathrm{NP}_{\mathrm{c}} \mathrm{K}$ & 153 & 56 & - & 11,2 \\
\hline 3 & $\mathrm{NP}_{л} \mathrm{~K}$ & 255 & 158 & 102 & 31,6 \\
\hline 4 & $\mathrm{NP}_{\mathrm{c}} \mathrm{K}+\mathrm{H}$ & 191 & 94 & 38 & 18,9 \\
\hline 5 & $\mathrm{NP}_{\mathrm{I}} \mathrm{K}+\mathrm{H}$ & 280 & 183 & 25 & 38,6 \\
\hline 6 & $\mathrm{NP}_{0,5 \mathrm{c}} \mathrm{K}$ & 125 & 28 & - & 11,2 \\
\hline 7 & $\mathrm{NP}_{0,5 л} \mathrm{~K}$ & 180 & 83 & 55 & 33,2 \\
\hline 8 & $\mathrm{NP}_{0,5 \mathrm{c}} \mathrm{K}+\mathrm{H}$ & 139 & 42 & 14 & 16,8 \\
\hline 9 & $\mathrm{NP}_{0,5 \pi} \mathrm{K}+\mathrm{H}$ & 195 & 98 & 15 & 39,4 \\
\hline 10 & $\mathrm{NK}+\mathrm{H}$ & 127 & 30 & & - \\
\hline \multicolumn{2}{|c|}{$\mathrm{HCP}_{0,95}$} & 8,8 & & & \\
\hline
\end{tabular}

In the experiment, an additional factor to the main (method of application) was also studied, manure as a mobilizing factor and a source of nutrients and an optimizer of the water-air regime of the soil. The yield increase with the traditional continuous method of applying fertilizers from manure (option 4) is $38 \mathrm{c} / \mathrm{ha}$, while with the belt method of applying them only $25 \mathrm{c} /$ ha (option 5). This indicates a weak manifestation of the mobilizing role of manure in the belt application of the full rate of phosphorus compared to the continuous application, and even less with its half-rate both in the continuous and in the 
belt application, the increase from which is $14-15 \mathrm{c} /$ ha, respectively (options $8-9$ ). It is noteworthy, that with the belt application of half the norm $(50 \mathrm{~kg} / \mathrm{ha})$ of phosphorus, a significantly higher yield increase of $83 \mathrm{c} /$ ha (option 7) was obtained compared to the option of the full norm of phosphorus with its continuous application (option 2), which is $56 \mathrm{c} / \mathrm{ha}$, respectively. In accordance with this, with the belt application of phosphorus fertilizers, the coefficient of phosphorus use by the plant from superphosphate (options 2 and 3 ) increases two and three times. The belt application only one superphosphate contributed to an increase in the coefficient of phosphorus utilization of it from 11.2 to $31.6 \%$, and when coapplied with manure to $36.6 \%$, which is a very significant increase. The combined application of manure with phosphorus fertilizer even with continuous application leads to a certain increase in the phosphorus utilization coefficient (by 6-7\%), which also indicates a noticeable mobilizing effect of manure on phosphorus superphosphate in conditions of low mobility in gray-earth soils (option 4).

The greatest increase in the phosphorus utilization rate $(39.4 \%)$ is observed when the half-norm of phosphorus is applied together with manure in a belt. This is probably due to the fact, that plants absorb phosphorus most productively and efficiently, which is closely concentrated to the root system, precisely at low application rates and its deficiency in the soil.

Table 2. The effect of the new technology of applying the main phosphorus fertilizer and manure on the quality of the potato crop.

\begin{tabular}{|c|c|c|c|c|c|c|c|}
\hline \multirow[t]{2}{*}{$\mathrm{N}$} & \multirow[t]{2}{*}{ Variants } & \multirow{2}{*}{$\begin{array}{c}\text { Starch } \\
\text { content, } \%\end{array}$} & \multicolumn{2}{|c|}{ Increase } & \multicolumn{3}{|c|}{ Структура урожая, \% } \\
\hline & & & $\begin{array}{l}\text { From } \\
\text { control, } \\
\%\end{array}$ & $\begin{array}{l}\text { From the } \\
\text { factor, } \%\end{array}$ & $\begin{array}{c}\text { Large } \\
\mathrm{D}>5 \mathrm{~cm}\end{array}$ & $\begin{array}{l}\text { Average } \\
\text { D } 3-5 \mathrm{~cm}\end{array}$ & $\begin{array}{c}\text { Small } \\
\mathrm{D}<3 \mathrm{~cm}\end{array}$ \\
\hline 1 & $\begin{array}{c}\text { Control } \\
\text { (without } \\
\text { fertilizers) }\end{array}$ & 15,5 & & & 30 & 28 & 42 \\
\hline 2 & $\mathrm{NP}_{\mathrm{c}} \mathrm{K}$ & 18,6 & 3,1 & & 41 & 31 & 28 \\
\hline 3 & $\mathrm{NP}_{\text {Л }} \mathrm{K}$ & 19,6 & 4,1 & 1,0 & 60 & 30 & 10 \\
\hline 4 & $\mathrm{NP}_{\mathrm{c}} \mathrm{K}+\mathrm{H}$ & 20,6 & 5,1 & 2,0 & 45 & 40 & 15 \\
\hline 5 & $\mathrm{NP}_{л} \mathrm{~K}+\mathrm{H}$ & 20,3 & 4,8 & 0,7 & 58 & 32 & 12 \\
\hline 6 & $\mathrm{NP}_{0,5 \mathrm{c}} \mathrm{K}$ & 16,5 & 1,0 & - & 40 & 30 & 30 \\
\hline 7 & $\mathrm{NP}_{0,5 л} \mathrm{~K}$ & 18,2 & 2,7 & 1,7 & 47 & 35 & 18 \\
\hline 8 & $\begin{array}{c}\mathrm{NP} \\
0,5 \mathrm{c}+\mathrm{H}\end{array}$ & 18,6 & 3,1 & 2,1 & 46 & 36 & 18 \\
\hline 9 & $\begin{array}{c}\mathrm{NP} \\
0,5 \pi \mathrm{K}+\mathrm{H}\end{array}$ & 18,9 & 3,4 & 0,7 & 53 & 38 & 9 \\
\hline 10 & $\mathrm{NK}+\mathrm{H}$ & 16,1 & 0,6 & - & 42 & 40 & 18 \\
\hline & $\mathrm{HCP}_{0,95}$ & 2,67 & & & & & \\
\hline
\end{tabular}

The obtained data on the starch content according to the variants of the experiment (Table. 2) in general, they are within the theoretical values (16-19\% for early varieties), which also include the studied variety. There is an opinion, that the values of the starch content in potatoes can be significantly influenced by the geographical (latitudinal) factor, varietal differences and dry matter content. Regarding the influence of other factors, especially with the method of applying fertilizers on the starch content, there is very little information in the literature. The research shows, that the difference in starch content between the non-fertilized option and the full-fertilized option ranges from $3.1-4 \%$, and together with manure 5.1-4.8 with continuous and tape application, respectively, which 
indicates an unconditional significant influence of the nutrition condition on the starch content in potato tubers.

As for the influence of the methods-the introduction of phosphorus fertilizers and manure on the starch content, it is insignificant in the range from 0.7 to $2 \%$, in favor of tape application, and sometimes vice versa (options 4 and 5), which is below the confidence criteria, i.e. within the analysis error.

Significantly low starch content, almost at the control level, in the phosphorus-free version with nitrogen-potassium fertilizer and manure (var. 10)

- $16.1 \%$, which indicates the important role of phosphorus on the quality of the crop, in particular the accumulation of starch in the tubers.

An equally important indicator of the quality of the potato crop is its structure, i.e. the size of the tubers. The result obtained in the experiment was divided into three qualitative groups

- small with a diameter of tubers less than $3 \mathrm{~cm}$; medium $-3-5 \mathrm{~cm}$ and large more than $5 \mathrm{~cm}$.

The results for this indicator show, that the relative proportion of large and mediumsized tubers increases directly as the yield increases, and small tubers increase proportionally as the yield decreases. This may indirectly indicate, that the increase in yield is mainly due to the enlargement of tubers, and not from an increase in their number.

\section{Conclusion}

The analysis of the structure of the soil cover and the bioclimatic potential of the irrigated zone of the Hissar Valley allowed us to identify land resources suitable and appropriate for early potato growing on an area of more than 23 thousand hectares where cotton farming may be inefficient. Growing early potatoes even on $30 \%$ of this area with an average yield of 170-180 c / ha, determined by the assessment of the soils of this region, can bring the production of marketable potatoes to 130 thousand tons per year, which is 23 times higher than its actual volume for ten years (1994-2003). In accordance with this, the conducted studies to identify the effectiveness of the new technology for applying the main phosphorus fertilizer and manure in full and half the norm showed, that the tape application of phosphorus fertilizers in comparison with traditional continuous applications will lead to a significant increase in the yield of early potatoes with an increase of more than $100 \mathrm{c} / \mathrm{ha}$ (at full rate) and $55 \mathrm{c} / \mathrm{ha}$ (at half rate). The combined application of $10 \mathrm{t} / \mathrm{ha}$ of semi-rotted manure with phosphors allows for an additional $25 \mathrm{t} / \mathrm{ha}$ of increase (at full norm) and $15 \mathrm{t} /$ ha (at $0.5 \mathrm{norm})$. With the introduction of a half-rate of phosphorus $(50 \mathrm{~kg} / \mathrm{ha})$, a yield increase of $26 \mathrm{c} /$ ha was obtained more than with the continuous application of the full rate $(100 \mathrm{~kg} / \mathrm{ha})$, which is extremely important in conditions of shortage and high cost of phosphorus fertilizers. These results are a direct consequence of a sharp (2-3 times) to increase the coefficient of the use of phosphorus from superphosphate in the belt method of its application and application together with manure. The research showed a significant dependence on the increase in the starch content in tubers when applying full mineral fertilizer compared to the variants without fertilizer for all variants of the experiment.

However, there is no positive correlation between the starch content and the fertilizer application method.

\section{References}

1. Statistical Collection (Dushanbe, 2004) 
2. R.D. Boboev, A. Abdualimov, N.U. Abidova, Methodological guidelines for soil valuation and economic assessment of the lands of Tajikistan (Dushanbe, 11-23, 2003)

3. Kh. D. Jumankulov, Problems of agrochemical monitoring in agriculture in Tajikistan (Dushanbe, 4-16, 1993)

4. I.N. Chumachenko, B.A. Sushchenitsa, U.R. Rakhmadjonov, The use of phosphorus from fertilizers, depending on the method of their application (M, 50, 40-51, 1971)

5. D.N. Pryanishnikov, Complete prefabricated isb., Works of T. (M, 1-111, 1952)

6. B.A. Dospekhov, Methodology of field experience (Moscow, 1973)

7. K. Partoev, M.K. Gulov, I. Nikhmonov, Ecological factors and productivity of potato, $3^{\text {rd }}$ International Conference ,Smart Bio “, Kaunas, Lithuania, Vytautas Magnus University, 118, (2019)

8. K. Partoev, M.K. Gulov, I. Nikhmonov, International Scientific Agricultural Journal, 1(1), 31-39 (2018) URL: http://isaj.ru/No1/20180105.pdf

9. M.Yu. Karpukhin, F. Keita, Agrarian Bulletin of the Urals, 19-23 (2020) DOI: 10.32417/1997-4868-2021-13-19-23

10. S.K. Mingalev, E.S. Tutenov, Agrarian Bulletin of the Urals, 6(160), 19-23 (2017) 